\title{
Comparison of the common bacteria in human and mouse tumours using high-throughput sequencing
}

\author{
FENGHAO ZHANG, MINGZHENG ZHANG, YUQING WANG, CHENGJIE LI and TINGTAO CHEN \\ Institute of Translational Medicine, Nanchang University, Nanchang, Jiangxi 330031, P.R. China
}

Received October 25, 2017; Accepted March 1, 2018

DOI: $10.3892 / \mathrm{mmr} .2018 .8689$

\begin{abstract}
Evidence has indicated that gut bacteria may serve an important role in cancer development and therapy, while little work has been done to explore the microbial diversity inside tumours. In the present study, high-throughput sequencing was first used to identify and compare the microbial diversity in human and mouse tumours. Principal component analysis (PCA) and $\beta$-diversity indicated a low microbial similarity among mouse artificial tumours (M.AT group), mouse spontaneous tumours (M.T group) and human tumours (H.T group), and Serratia (35.85 vs. 32.64 vs. $73.32 \%$ ), Pseudomonas (24.10 vs. 16.62 vs. $1.72 \%$ ) and Ochrobactrum (6.28 vs. 11.08 vs. $11.90 \%$ ) were identified as dominant bacteria at the genus level. In addition, Venn results indicated 103 common operational taxonomic units (OTUs) in the M.AT, M.T and H.T groups, and only 2 and 1 OTUs belonged to Lactobacillus and Escherichia, respectively, while no OTUs belonging to Salmonella, Bifidobacteria or Clostridium were identified. In the present study, the common bacteria between human and mouse tumours were identified, which may serve as potential strains for bacteriotherapy of cancers.
\end{abstract}

\section{Introduction}

Cancer is one of the most common causes of death in developed countries (1), and recent researches showed that gut bacteria seriously influenced the treatment and outcomes for patients with advanced malignancies (2). Researchers provided strong evidence of the role of stool microbiota in response and resistance to immunotherapy (3-5), and Bacteroidales and Bifidobacterium greatly increased the number and activity of immune cells, which then promoted the efficacy of anti-CTLA-4 and anti-PD-L1 therapy (6).

Do the microbiota inside tumours also play an important role in cancer development and therapy? It has been

Correspondence to: Dr Tingtao Chen, Institute of Translational Medicine, Nanchang University, 1299 Xuefu Road, Honggu, Nanchang, Jiangxi 330031, P.R. China

E-mail: chentingtao1984@163.com

Key words: high-throughput sequencing, cancer, microbial diversity, Clostridium novyi, Salmonella typhimurium recognized for more than 60 years that the tumour microenvironment creates an ideal condition for the growth of anaerobic and some facultative anaerobic bacteria (7), and several approaches to developing anaerobic bacteria for tumour therapies have been described (8-10). Until now, the anaerobic species of Bifidobacterium longum, lactic acid bacteria, Clostridium novyi and Salmonella typhimurium have been used as an anticancer protein-delivery agent to repress tumour growth for their selective growth in the hypoxic environment of large solid tumours (11-14). However, two clinical trials indicated that Salmonella failed to fully colonize human tumours, conflicting with the observation made for murine models for some unknown reasons $(15,16)$.

As we know, the mouse model is a powerful tool in biological evaluation, while the species differences between humans and mice often result in the failure of some drug evaluations. Some researchers have indicated that functional differences might be the reason for the failure of two clinical Salmonella trials $(15,16)$, therefore it is crucial to find the bacteria that are common to both human and mice tumours, which may serve as sound anticancer protein-delivery agents.

So far, though medical microbiologists have relied on culture techniques for decades, these culture methods can only be used for identifying the 'culturable' bacteria that grow relatively quickly and easily in laboratory media $(17,18)$ because of their various nutritional, $\mathrm{pH}$, temperature and oxygen requirements, and the interspecies competition and different concentrations of bacteria within a plate also increase difficulties with screening $(19,20)$. To determine the full panoply of organisms within tumours, high-throughput sequencing methods may be useful since they can detect almost all the DNA signatures of micro-organisms within a specific environment, even some of them with low numbers or a dormant metabolic state (21-23).

In the present study, the high-throughput sequencing method was applied and the bacterial diversity in human and mice tumours was compared. In addition, the common bacteria in human and mice tissues were identified and these might be used as the potential strain to solve the host's problems of incompatibility in relation to bacteriotherapy of cancer.

\section{Materials and methods}

Ethical statement. Patient samples were obtained with written informed consent in accordance with the Ethics Committee requirements at the participating institutes and the Declaration 
of Helsinki. Permission to carry out the study was obtained from the Institutional Review Board (IRB) of the Second Affiliated Hospital of Nanchang University.

This study was carried out in strict accordance with the recommendations in the Guide for the Care and Use of Laboratory Animals of the National Institutes of Health. The protocol was approved by the Committee on the Ethics of Animal Experiments of the Second Affiliated Hospital of Nanchang University.

Artificial tumour samples in a mice model (M-Artificial tumour, M.AT group). $\mathrm{H} 22$ cells (BALB/c background, ATCC, USA) were cultured in a humidified incubator at $37^{\circ} \mathrm{C}$ under $5 \% \mathrm{CO}_{2}$ in RPMI 1640 supplemented with $10 \%$ heat-inactivated foetal bovine serum, $2 \mathrm{mmol} / 1$ glutamine, $100 \mathrm{U} / \mathrm{ml}$ penicillin and $100 \mathrm{U} / \mathrm{ml}$ streptomycin (14).

Mice (6 SPF-class KM male mice weighing from 18 to $22 \mathrm{~g}$, 8 weeks) were kept under standardized conditions $\left(22-24^{\circ} \mathrm{C}\right.$ temperature; $55 \pm 15 \%$ humidity) in a $12 \mathrm{~h}$ light $/ 12 \mathrm{~h}$ dark cycle in groups of three in an enriched environment (social enrichment, structured bedding, mouse house with nested material). Food and tap water were provided ad libitum. To establish a solid tumour model, each mouse was inoculated with $0.2 \mathrm{ml}$ $\mathrm{H} 22$ tumour cell suspension $\left(1 \times 10^{6} / \mathrm{ml} \mathrm{PBS}\right)$ by s.c. injection to the right flank. At the end of 2 weeks, the mice were sacrificed and soaked in $75 \%$ ethanol for $5 \mathrm{~min}$ in a biosafety cabinet, and the tumour xenografts (one tumor per mouse, ranging from 2,500 to $3,000 \mathrm{~mm}^{3}$, no signs of distress and no tumor ulceration was observed) were sterilely removed and stored at $-20^{\circ} \mathrm{C}$ for future use (24).

Spontaneous tumour samples in mice [M-tumour group (M.T group)]. Mice (6 SPF-class KM mice, aged from 8 to 50 weeks) with spontaneous tumors (one tumor per mouse, ranging from 2,000 to $3,100 \mathrm{~mm}^{3}$, no signs of distress and no tumor ulceration was observed) were provided by the Experimental Animal Center of Nanchang University, and were kept under standardized conditions $\left(22-24^{\circ} \mathrm{C}\right.$ temperature; $55 \pm 15 \%$ humidity) in a $12 \mathrm{~h}$ light $/ 12 \mathrm{~h}$ dark cycle in groups of three in an enriched environment (social enrichment, structured bedding, mouse house with nested material). Food and tap water were provided ad libitum. The tumour samples were sterilized separately from the mice and stored at $-20^{\circ} \mathrm{C}$ for future use $(n=6)$.

Tumour samples from patients [H-tumour group (H.T group)]. From a total of six patients with diagnosed liver cancer (without bacterial infection, viral and alcoholic hepatitis), tumour samples were collected by tumour excision surgery. Then the samples were stored in disposable sterile tubes and immediately transferred into the refrigerator at $-20^{\circ} \mathrm{C}$ for bacterial DNA extraction.

Total genomic DNA extraction and high-throughput sequencing. Sample DNA was extracted from the samples using a TIANamp Genomic DNA kit (Tiangen Biotech Co., Ltd., Beijing, China) according to the manufacturer's instructions. To avoid the loss of microbial diversity caused by the small amount of bacteria in the tumours, all the collected tumours in the same group were mixed and cut into small pieces and homogenized in $500 \mu \mathrm{l} \mathrm{GA}$ with $0.2 \mathrm{~g}$ micro glass beads and centrifuged at $1,000 \mathrm{~g}$ for $2 \mathrm{~min}$. Then the mixtures were transferred into new columns of $1.5 \mathrm{ml}$. A total of $20 \mu \mathrm{l}$ of proteinase $\mathrm{K}$ solution $(20 \mathrm{mg} / \mathrm{ml})$ was added, vortexed to mix, and then incubated at room temperature for approximately $5 \mathrm{~min}$. The Buffer GB provided in the kit $(200 \mu \mathrm{l})$ was added and vortexed for $5 \mathrm{~min}$. The samples were then placed in a temperature of $70^{\circ} \mathrm{C}$ for 10 to $15 \mathrm{~min}$. Then $200 \mu \mathrm{l}$ of ethyl alcohol were added and agitated for $15 \mathrm{sec}$. The mixtures were transferred into Spin Columns CB3 with a $2 \mathrm{ml}$ collection tube and centrifuged at 10,000 g for $30 \mathrm{sec}$. The flow-through liquid was discarded. Then $500 \mu \mathrm{l}$ of buffer GD was added and centrifuged at 10,000 $\mathrm{g}$ for $30 \mathrm{sec}$. After discarding the flow-through liquid, $600 \mu \mathrm{l}$ of wash buffer PW was added and centrifuged at $10,000 \mathrm{~g}$ for $30 \mathrm{sec}$. Placed spin columns CB3 for $30 \mathrm{~min}$ and added $100 \mu \mathrm{l}$ of elution buffer at room temperature for $2 \mathrm{~min}$. The column was then centrifuged for $2 \mathrm{~min}$ at $10,000 \mathrm{~g}$ and stored at $-20^{\circ} \mathrm{C}$ for future analysis.

Total genomic DNA was amplified using a 515f/806r primer set that amplifies the V4 region of the $16 \mathrm{~S}$ rDNA gene $(25,26)$. The forward primer contains a $6 \mathrm{bp}$ error-correcting barcode unique to each sample. DNA was amplified and 16S rRNA tag-encoded high-throughput sequencing was carried out using the Illumina MiSeq platform at Beijing Novogene Bioinformatics Technology Co., Ltd. (Beijing, China).

Bioinformatics and multivariate statistics. Paired-end reads from the original DNA fragments were merged using FLASH to merge paired-end reads when at least some of the reads overlapped the read generated from the opposite end of the same DNA fragment, and paired-end reads were assigned to each sample according to the unique barcodes.

Then, sequence analysis was performed utilizing the UPARSE software package using the UPARSE-operational taxonomic unit (OTU) and UPARSE-OTUref algorithms. In-house Perl scripts were used to analyse $\alpha$ (within samples) and $\beta$ (among samples) diversity. Sequences with $\geq 97 \%$ similarity were assigned to the same OTUs. A sequence was picked as a representative for each OTU, and the RDP classifier was used to annotate taxonomic information for each representative sequence. Cluster analysis was preceded by unweighted UniFrac distance using the QIIME software package.

\section{Results}

Shared genera and bacterial communities in human and mice tumours. To compare the microbes in human and mice tumours, 16S rRNA amplicon sequencing analysis was used to sequence the V4 hypervariable region. The sequencing data was filtered to get the valid data, and all the effective tags of all samples were clustered and those sequences with over $97 \%$ similarity were considered as one OTU. In total, 380,296 usable raw sequences (1,893 unique sequences) and 678 OTUs were obtained from all the samples with an average of 226 OTUs per group (Table I). Moreover, the Chaol index and Shannon index were nearly saturated and the rarefaction curve of every sample was able to enter the plateau phase, which indicated that the sequencing data was reasonable and the species composition was highly uniform in each group (data not shown). 
Table I. Number of total tags, taxon tags, unclassified tags, unique tags and operational taxonomic units from tumours by high-throughput sequencing.

\begin{tabular}{|c|c|c|c|c|c|}
\hline Group & Total tags & Taxon tags & $\begin{array}{c}\text { Unclassified } \\
\text { tags }\end{array}$ & $\begin{array}{l}\text { Unique } \\
\text { tags }\end{array}$ & OTUs \\
\hline M.AT & $133,150.00$ & $132,546.00$ & 0.00 & 604.00 & 244.00 \\
\hline M.T & $55,113.00$ & $54,667.00$ & 8.00 & 438.00 & 226.00 \\
\hline H.T & $192,033.00$ & $191,182.00$ & 0.00 & 851.00 & 208.00 \\
\hline Mean & $126,765.30$ & $126,131.70$ & 2.67 & 631.00 & 226.00 \\
\hline Total & $380,296.00$ & $378,395.00$ & 8.00 & $1,893.00$ & 678.00 \\
\hline
\end{tabular}

OTUs, operational taxonomic units; M.AT, mouse artificial tumours; M.T, mouse spontaneous tumours; H.T, human tumours.

At the phylum level, the data of the top ten micro-organism populations was analysed. As shown in Fig. 1, Proteobacteria constituted the predominant phylum in the M.AT, M.T and H.T groups, which accounted for 95.8, 97 and 89\%, respectively, of the total sequencing number in these three groups.

The $\beta$ diversity of the microbial community in human and mice tumours. Principal component analysis (PCA) of both human and mice tumours was conducted, and a closer distance of samples indicated a more similar bacterial composition. As shown in Fig. 2A, though the M.AT, M.T and H.T groups were scattered far from each other, the heatmap of $\beta$ diversity indicated that the microbial community among mice tumours (M.AT vs. M.T, 0.102) was closer than that of M.AT vs. H.T (0.114) and M.T vs. H.T (0.135) (Fig. 2B).

Compositions and relative abundance of bacterial communities in human and mice tumours. To further investigate the relative microbial abundance in the M.AT, M.T and H.T groups, the top 10 genera were clustered. As shown in Fig. 3, the dominant bacterial genera in the M.AT group were Serratia (32.64\%), Pseudomonas (16.62\%), Ochrobactrum (11.08\%), Cupriavidus (10.72\%), Methylobacterium (3.45\%) and Phyllobacterium (2.33\%), while Serratia (73.32\%), Pseudomonas (1.72\%), Ochrobactrum (11.90\%) and Phyllobacterium (2.36\%) were predominant in the M.T group. For the H.T group, Serratia (35.85\%), Pseudomonas (24.10\%), Ochrobactrum (6.28\%), Escherichia (8.32\%), Methylobacterium (2.38\%), Phyllobacterium (1.59\%) and Sphingomonas $(1.35 \%)$ were identified as the dominant bacteria. In addition, the bacteria classified as 'others' had accounted for $14.21,6.90$ and $17.38 \%$ of the total sequencings.

The specificity of bacterial communities in human and mice tumours. The Venn figure.reflecting the difference between human and mice tumours depicted, as shown in Fig. 4, that there were 217, 216 and 180 OTUs in the M.AT, M.T and H.T groups, respectively. A comparison between all groups indicated that 103 common OTUs had been identified, of which 2, 0, 1 and 0 OTUs belonged to Lactobacillus, Salmonella, Escherichia and Clostridium, respectively. Therefore, the no detection of Salmonella and Clostridium in either human or mouse tumours suggests that these two strains were not a good choice for anticancer therapies.

\section{Discussion}

Tumours are composed of necrotic, hypoxic and hypoxic areas offering a perfect niche for the growth of anaerobic bacteria (10). Since Coley's original work treating cancer patients with Streptococcus pyogenes over 100 years ago, a variety of anaerobic bacteria have been considered for this purpose but failed in part because of poor reproducibility and unacceptable toxicity (27-29). More recent work involved attenuated strains of $S$. typhimurium, while the phase 1 clinical trials of S. typhimurium received limited efficacy, though the bacterium could be safely administered and targeted at tumours in both dogs and human patients $(16,30)$. Moreover, recent studies indicated that bacteria imbalance (dysbiosis) did affect oncogenesis, tumour progression and cancer therapy $(3,6,31)$. Unfortunately, little work has been done to explore the microbial diversity inside tumours and clarify their potential roles in tumour development and therapy.

To the best of our knowledge, the distribution of bacteria, e.g., Bifidobacterium longum, lactic acid bacteria, Clostridium novyi and Salmonella typhimurium, was mainly affected by the volume of solid tumours rather than tumour sites and types $(32,33)$, so the microbial diversity in solid tumours in humans and mice was compared using high-throughput sequencing. For convenience of sampling, liver cancer, the second leading cause of cancer death, was collected both from humans and mice. Moreover, as the low microbial amount and rich tumour stroma and blood vessels would lead to a huge loss of DNAs, which would finally reduce the biodiversity of the bacterial community in tumours, all the samples collected from the same different tissues were mixed and a mean number of 378,395 usable sequences and the saturated Chaol index and Shannon index (Table I) ensured their reliability for future analysis. Even so, more advanced DNA extraction method will be applied in our further work to expand the sample size and sustain the individual difference, and the fluorescence in situ hybridization (FISH) will be used to locate the bacterial position in liver tumors.

As shown in Fig. 1, Proteobacteria accounted for 95.8, 97 and $89 \%$, respectively, of the total sequencing number in the M.AT, M.T and H.T groups. Proteobacteria are a major group of gram-negative bacteria and include a wide variety of pathogens, such as Escherichia, Salmonella, Vibrio, Helicobacter and Yersinia, and some of this phylum is responsible for nitrogen fixation (34). However, this group has been detected as the dominant population in the human intestine and oral cavity $(26,35)$, so much more work needs to be done to explore its potential effects on human health or diseases (including cancer).

In Fig. 2, the widely scattered PCA symbols of M.AT, M.T and H.T showed an obviously low similarity in the microbial community in these three groups, though the $\beta$ diversity index indicated that the microbial community in mice was much closer than that in different species. Therefore, the obviously different microbial community between humans and mice (even the microbial communities of spontaneous tumours and artificial tumours were obviously different) indicated 


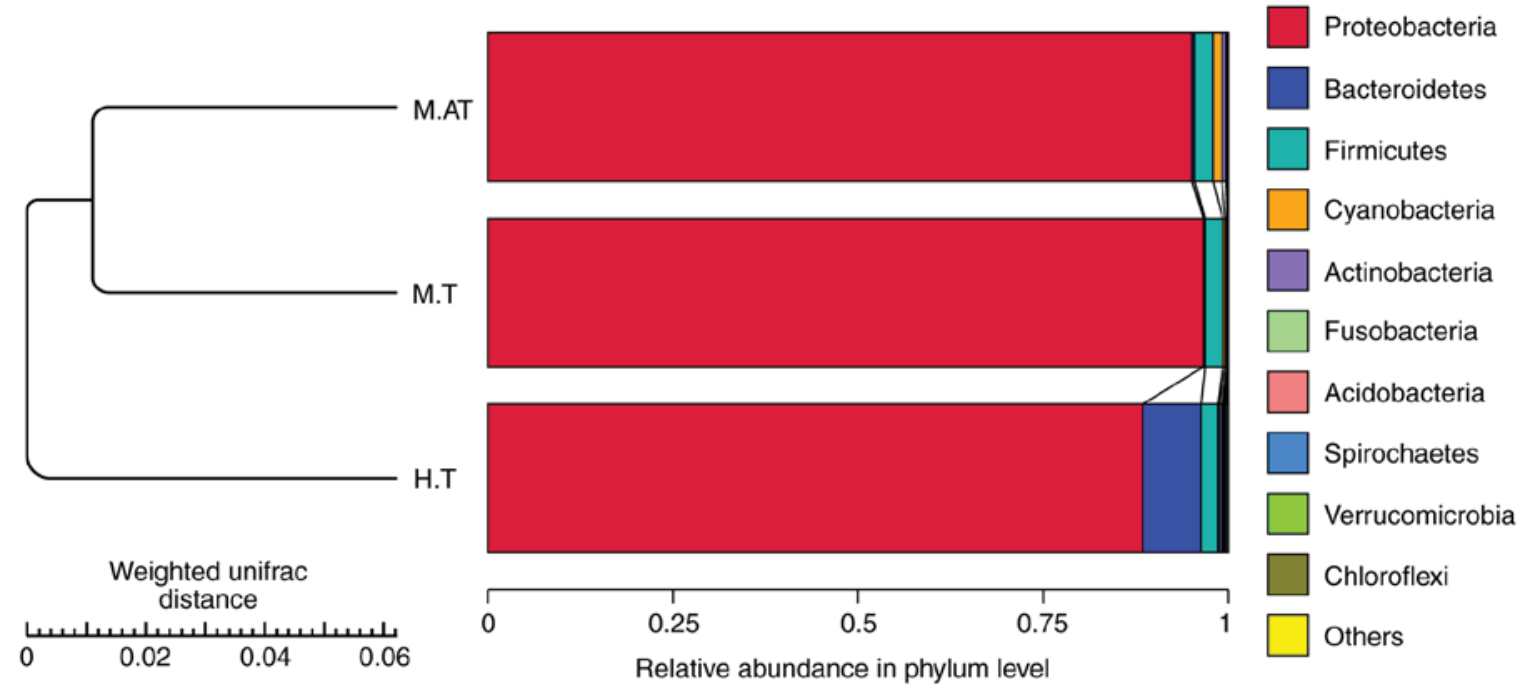

Figure 1. Composition and relative abundance of bacterial communities-based 16S rDNA sequences in the M.AT, M.T and H.T groups at the phylum level. The results indicated that the bacterial diversity in mouse tumours (M.AT and M.T groups) was markedly different to that observed in human tumours, and Proteobacteria constituted $95.8,97$ and $89 \%$, respectively, of the total sequencing number in the M.AT, M.T and H.T groups. M.AT, mouse artificial tumours; M.T, mouse spontaneous tumours; H.T, human tumours.
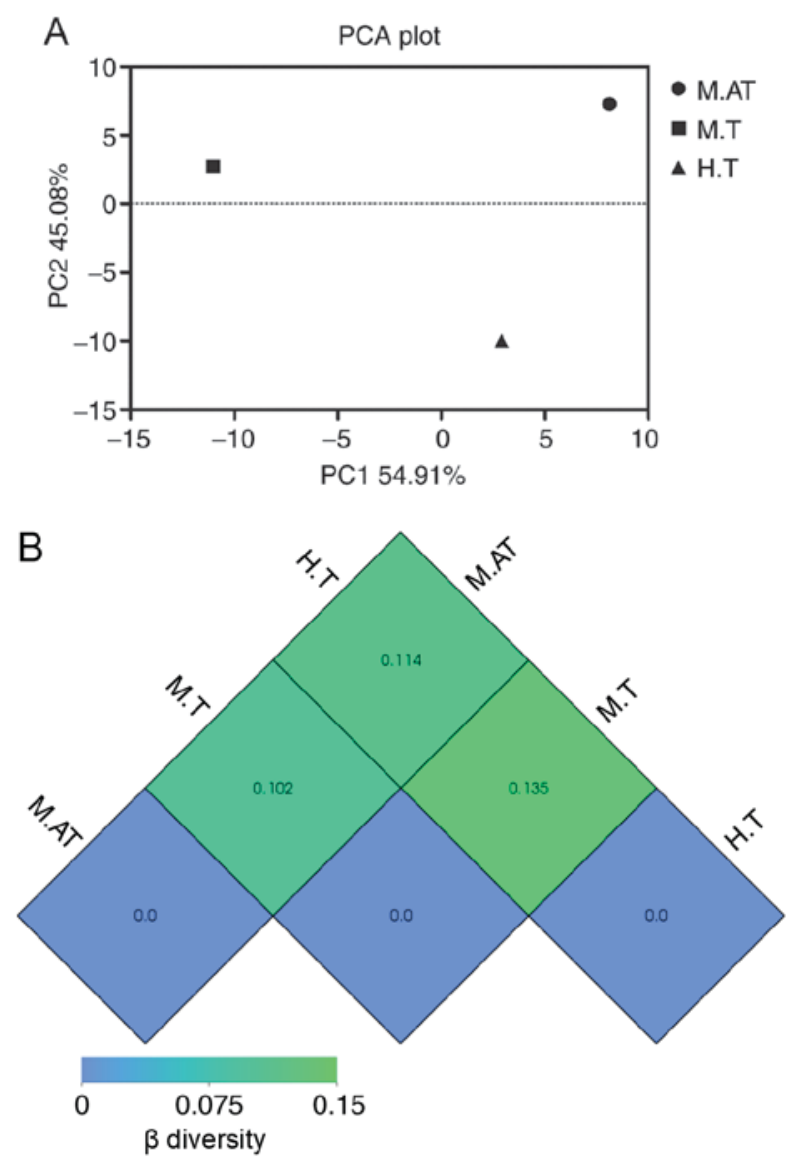

Figure 2. (A) PCA and (B) heatmap of b-diversity index of the M.AT, M.T and H.T groups. The results indicated that bacterial diversity in the M.AT, M.T and H.T groups varied, while the microbial communities among mouse tumours (M.AT vs. M.T) were closer than M.AT vs. H.T and M.T vs. H.T. M.AT, mouse artificial tumours; M.T, mouse spontaneous tumours; H.T, human tumours; PCA, principal component analysis.

that the tumour size and microenvironment (e. g. oxygen and $\mathrm{pH})$ might create different survival environments for different

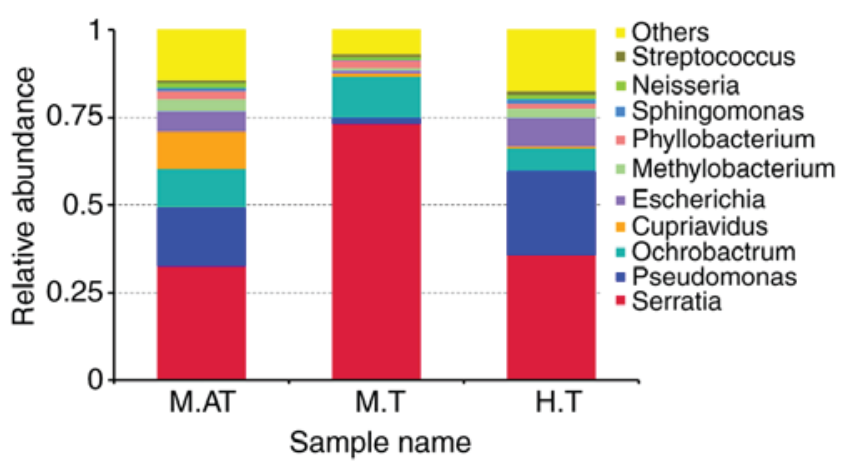

Figure 3. Relative abundance of the bacteria among the M.AT, M.T and H.T groups at the genus level. The results indicated that Serratia, Pseudomonas and Ochrobactrum were predominant in the M.AT, M.T and H.T groups. M.AT, mouse artificial tumours; M.T, mouse spontaneous tumours; H.T, human tumours.

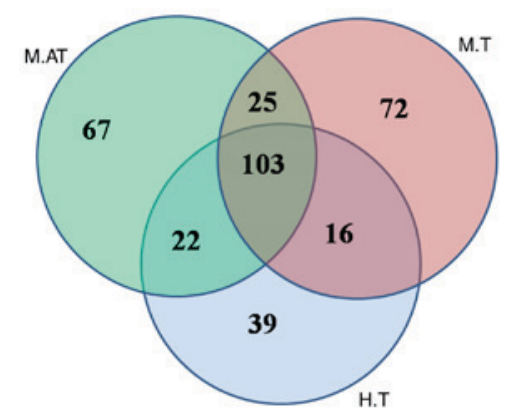

Figure 4. Scalar-Venn representation of the tumour microbiota among the M.AT, M.T and H.T groups. The results indicated that there were 217, 216 and 180 OTUs in the M.AT, M.T and H.T groups; 103 common OTUs in these groups have been identified. M.AT, mouse artificial tumours; M.T, mouse spontaneous tumours; H.T, human tumours; OTUs, operational taxonomic units.

micro-organisms, and the low similarity among the M.AT, M.T and H.T groups partly explained the failure of the phase 1 clinical trials of S. typhimurium. 
Then, data of the top ten micro-organism populations was analysed at the genus level. Just as expected, the microbial composition in human tumours and artificial mice tumours was obviously different, however Serratia (35.85 vs. $32.64 \%$ ), Pseudomonas (24.10 vs. 16.62\%), Ochrobactrum (6.28 vs. $11.08 \%$ ) had been identified as the dominant bacteria in human tumours and artificial tumours. Interestingly, the microbial composition of the M.T group was obviously different to that of the H.T and M.AT groups at the genus level, and Serratia and Ochrobactrum accounted for 73.32 and $11.90 \%$ of the total sequencings, respectively (Fig. 3). As we know, Serratia is a genus of facultative anaerobic bacteria of the Enterobacteriaceae family, and can be distinguished from other members of the Enterobacteriaceae family by their unique production of three enzymes: DNase, lipase and gelatinase (36). Pseudomonas belongs to the Pseudomonadaceae family containing 191 valid species, and they demonstrate a great deal of metabolic diversity, and consequently are able to colonize a wide range of niches (37). Interestingly, Streptococcus, the first genus used to treat cancer patients 100 years ago, accounted for $0.7-1.0 \%$ of the total number in these three groups.

To find the common bacteria between human and mice tumours, the bacterial compositions were compared. In Fig. 4, the Venn figure reflected 103 common OTUs in the M.AT, M.T and H.T groups, and only two and one OTUs belonged to Lactobacillus and Escherichia, and no OTUs belonging to Salmonella, Bifidobacteria and Clostridium were found. As we know, Streptococcus, Lactobacillus, Escherichia, Salmonella, Bifidobacteria and Clostridium have been used as vectors for gene therapy of cancer (10,38-40), therefore the existence of Streptococcus, Lactobacillus and Escherichia both in humans and mice showed their potential value for animal and human verification. Especially for Lactobacillus, whose most members had been used in the preparation of fermented foods and these microorganisms were generally considered safe (41).

In conclusion, our results indicated that various bacteria exist both in human and mice tumours, and the significantly different bacterial composition in artificial mice tumours, spontaneous mice tumours and human tumours may partly explain the sound effect of attenuated Salmonella in murine models and the unsatisfactory observation in human tumours. However, our work indicated that the common bacteria of Streptococcus, Lactobacillus and Escherichia both in human and mice tumours might be used as potential strains in the immunotherapy and bacteriotherapy of cancers.

\section{Acknowledgements}

The authors would like to thank Dr Bin Xie (Jiangxi University of Traditional Chinese Medicine) and Miss Lin Xie (Nanchang University) for providing the mouse and human tumors, as well as all of the members in Dr Chen's Laboratory (Institute of Translational Medicine) for their generous help and valuable discussion.

\section{Funding}

The present study was supported by grants from The National Natural Science Foundation of China (grant nos. 81503364 and 31560264) and Excellent Youth Foundation of Jiangxi Scientific Committee (grant no. 20171BCB23028), and Science and Technology Plan of Jianxi Health Planning Committee (grant no. 20175526).

\section{Availability of data and materials}

All data generated or analyzed during this study are included in this published article.

\section{Authors' contributions}

TC designed the experiments, analysed the data and wrote the manuscript. FZ, MZ, YW and CL performed the experiments. All authors discussed the results and commented on the final manuscript.

\section{Ethics approval and consent to participate}

The protocol was approved by the Committee on the Ethics of Animal Experiments of the Second Affiliated Hospital of Nanchang University (Jiangxi, China). Patient samples were obtained with written informed consent in accordance with the Ethics Committee's requirements.

\section{Consent for publication}

Written informed consent was obtained from all participants.

\section{Competing interests}

The authors declare that they have no competing interests.

\section{References}

1. Williams NS, Bailey H, Bulstrode CJ, Love RM and O'Connell PR (eds): Bailey \& Love's Short Practice of Surgery. CRC Press, Boca Raton, FL, 2008.

2. Postow MA, Chesney J, Pavlick AC, Robert C, Grossmann K, McDermott D, Linette GP, Meyer N, Giguere JK, Agarwala SS, et al: Nivolumab and ipilimumab versus ipilimumab in untreated melanoma. N Engl J Med 372: 2006-2017, 2015.

3. Sivan A, Corrales L, Hubert N, Williams JB, Aquino-Michaels K, Earley ZM, Benyamin FW, Lei YM, Jabri B, Alegre ML, et al: Commensal Bifidobacterium promotes antitumor immunity and facilitates anti-PD-L1 efficacy. Science 350: 1084-1089, 2015

4. Hoos A: Development of immuno-oncology drugs-from CTLA4 to PD1 to the next generations. Nat Rev Drug Discov 15: 235-247, 2016.

5. Vétizou M, Pitt JM, Daillère R, Lepage P, Waldschmitt N, Flament C, Rusakiewicz S, Routy B, Roberti MP, Duong CP, et al: Anticancer immunotherapy by CTLA-4 blockade relies on the gut microbiota. Science 350: 1079-1084, 2015.

6. Maynard CL, Elson CO, Hatton RD and Weaver CT: Reciprocal interactions of the intestinal microbiota and immune system. Nature 489: 231-241, 2012.

7. Wei MQ, Mengesha A, Good D and Anné J: Bacterial targeted tumour therapy-dawn of a new era. Cancer Lett 259: 16-27, 2008.

8. Gur C, Ibrahim Y, Isaacson B, Yamin R, Abed J, Gamliel M, Enk J, Bar-On Y, Stanietsky-Kaynan N, Coppenhagen-Glazer S, et al: Binding of the Fap2 protein of Fusobacterium nucleatum to human inhibitory receptor TIGIT protects tumors from immune cell attack. Immunity 42: 344-355, 2015.

9. Frahm M, Felgner S, Kocijancic D, Rohde M, Hensel M, Curtiss R III, Erhardt M and Weiss S: Efficiency of conditionally attenuated Salmonella enterica serovar Typhimurium in bacterium-mediated tumor therapy. MBio 6: pii: e00254-15, 2015. 
10. Roberts NJ, Zhang L, Janku F, Collins A, Bai RY, Staedtke V, Rusk AW, Tung D, Miller M, Roix J, et al: Intratumoral injection of Clostridium novyi-NT spores induces antitumor responses. Sci Transl Med 6: 249ra111, 2014.

11. Zeuthen LH, Christensen HR and Frøkiær H: Lactic acid bacteria inducing a weak interleukin-12 and tumor necrosis factor alpha response in human dendritic cells inhibit strongly stimulating lactic acid bacteria but act synergistically with gram-negative bacteria. Clin Vaccine Immunol 13: 365-375, 2006.

12. Fox M, Lemmon M, Mauchline M, Davis TO, Giaccia AJ, Minton NP and Brown JM: Anaerobic bacteria as a delivery system for cancer gene therapy: In vitro activation of 5-fluorocytosine by genetically engineered clostridia. Gene Ther 3 : 173-178, 1996.

13. Low KB, Ittensohn M, Le T, Platt J, Sodi S, Amoss M, Ash O, Carmichael E, Chakraborty A, Fischer J, et al: Lipid A mutant Salmonella with suppressed virulence and TNFv induction retain tumor-targeting in vivo. Nat Biotechnol 17: 37-41, 1999.

14. Zhao M, Yang M, Li XM, Jiang P, Baranov E, Li S, Xu M, Penman S and Hoffman RM: Tumor-targeting bacterial therapy with amino acid auxotrophs of GFP-expressing Salmonella typhimurium. Proc Natl Acad Sci USA 102: 755-760, 2005.

15. Nemunaitis J, Cunningham C, Senzer N, Kuhn J, Cramm J, Litz C, Cavagnolo R, Cahill A, Clairmont C and Sznol M: Pilot trial of genetically modified, attenuated Salmonella expressing the $E$. coli cytosine deaminase gene in refractory cancer patients. Cancer Gene Ther 10: 737-744, 2003.

16. Toso JF, Gill VJ, Hwu P, Marincola FM, Restifo NP, Schwartzentruber DJ, Sherry RM, Topalian SL, Yang JC, Stock F, et al: Phase I study of the intravenous administration of attenuated Salmonella typhimurium to patients with metastatic melanoma. J Clin Oncol 20: 142-152, 2002.

17. McGuckin M, Goldman R, Bolton L and Salcido R: The clinical relevance of microbiology in acute and chronic wounds. Adv Skin Wound Car 16: 12-25, 2003.

18. Thomson PD: Immunology, microbiology, and the recalcitrant wound. Ostomy Wound Manage 46 (1A Suppl): 77S-84S, 2000.

19. Whitley R: The new age of molecular diagnostics for microbial agents. N Engl J Med 358: 988-989, 2008.

20. Davies CE, Hill KE, Wilson MJ, Stephens P, Hill CM, Harding KG and Thomas DW: Use of $16 \mathrm{~S}$ ribosomal DNA PCR and denaturing gradient gel electrophoresis for analysis of the microfloras of healing and nonhealing chronic venous leg ulcers. J Clin Microbiol 42: 3549-3557, 2004

21. Kobayashi N, Bauer TW, Tuohy MJ, Lieberman IH, Krebs V, Togawa D, Fujishiro T and Procop GW: The comparison of pyrosequencing molecular Gram stain, culture, and conventional Gram stain for diagnosing orthopaedic infections. J Orthop Res 24: 1641-1649, 2006.

22. Zhang C, Zhang M, Pang X, Zhao Y, Wang L and Zhao L: Structural resilience of the gut microbiota in adult mice under high-fat dietary perturbations. ISME J 6: 1848-1857, 2012.

23. Wang T, Cai G, Qiu Y, Fei N, Zhang M, Pang X, Jia W, Cai S and Zhao L: Structural segregation of gut microbiota between colorectal cancer patients and healthy volunteers. ISME J 6: 320-329, 2012.

24. Zhao A, Nunez-Cruz S, Li C, Coukos G, Siegel DL and Scholler N: Rapid isolation of high-affinity human antibodies against the tumor vascular marker Endosialin/TEM1, using a paired yeast-display/secretory scFv library platform. J Immunol Methods 363: 221-232, 2011.
25. Sun M, Xiao T, Ning Z, Xiao E and Sun W: Microbial community analysis in rice paddy soils irrigated by acid mine drainage contaminated water. Appl Microbiol Biotechnol 99: 2911-2922, 2015

26. Yu X, Wu X, Qiu L, Wang D, Gan M, Chen X, Wei H and Xu F. Analysis of the intestinal microbial community structure of healthy and long-living elderly residents in Gaotian Village of Liuyang City. Appl Microbiol Biotechnol 99: 9085-9095, 2015.

27. Coley WB: The treatment of inoperable sarcoma by bacterial toxins (the mixed toxins of the Streptococcus erysipelas and the Bacillus prodigiosus). Proc R Soc Med 3 (Surg Sect): 1-48, 1910.

28. Coley WB: The treatment of malignant tumors by repeated inoculations of erysipelas. With a report of ten original cases. 1893. Clin Orthop Relat Res 262: 3-11, 1991.

29. Hoffman RM and Zhao M: Methods for the development of tumor-targeting bacteria. Expert Opin Drug Discov 9: 741-750, 2014.

30. Thamm DH, Kurzman ID, King I, Li Z, Sznol M, Dubielzig RR, Vail DM and MacEwen EG: Systemic administration of an attenuated, tumor-targeting Salmonella typhimurium to dogs with spontaneous neoplasia: Phase I evaluation. Clin Cancer Res 11: 4827-4834, 2005.

31. Iida N, Dzutsev A, Stewart CA, Smith L, Bouladoux N, Weingarten RA, Molina DA, Salcedo R, Back T, Cramer S, et al: Commensal bacteria control cancer response to therapy by modulating the tumor microenvironment. Science 342: 967-970, 2013.

32. Lee $\mathrm{CH}$ : Engineering bacteria toward tumor targeting for cancer treatment: Current state and perspectives. Appl Microbiol Biotechnol 93: 517-523, 2012.

33. Singh R and Paterson Y: Listeria monocytogenes as a vector for tumor-associated antigens for cancer immunotherapy. Expert Rev Vaccine 5: 541-552, 2006.

34. Stackebrandt E, Murray R and Trüper H: Proteobacteria classis nov., a name for the phylogenetic taxon that includes the 'purple bacteria and their relatives'. Int J Syst Bacteriol 38: 321-325, 1988.

35. Diaz PI, Dupuy A, Abusleme L, Reese B, Obergfell C, Choquette L, Dongari-Bagtzoglou A, Peterson DE, Terzi E and Strausbaugh LD: Using high throughput sequencing to explore the biodiversity in oral bacterial communities. Mol Oral Microbiol 27: 182-201, 2012.

36. Grimont PA and Grimont F: The genus Serratia. Annu Rev Microbiol 32: 221-248, 1978.

37. EUZéBY JP: List of bacterial names with standing in nomenclature: A folder available on the internet. Int J Syst Bacteriol 47: 590-592, 1997.

38. Baban CK, Cronin M, O'Hanlon D, O'Sullivan GC and Tangney M: Bacteria as vectors for gene therapy of cancer. Bioeng Bugs 1: 385-394, 2010.

39. Zu C and Wang J: Tumor-colonizing bacteria: A potential tumor targeting therapy. Crit Rev Microbiol 40: 225-235, 2014.

40. Bolhassani A and Zahedifard F: Therapeutic live vaccines as a potential anticancer strategy. Int J Cancer 131: 1733-1743, 2012.

41. Zhang W, Wang C, Huang C, Yu Q, Liu H, Zhang C and Pei X: Construction and expression of food-grade $\beta$-galactosidase gene in Lactococcus lactis. Curr Microbiol 62: 639-644, 2011. 